\title{
DESAFIOS DA PÓS-GRADUAÇÃO: ARTICULAÇÃO ENTRE ENSINO, PESQUISA E EXTENSÃO E DIÁLOGO COM OUTRAS FORMAS DE PRODUÇÃO DO CONHECIMENTO
}

\section{CHALLENGES OF GRADUATE: ARTICULATION BETWEEN EDUCATION, RESEARCH AND EXTENSION AND DIALOGUE OTHER FORMS OF KNOWLEDGE PRODUCTION}

\author{
NUNES, Flaviana Gasparotti. \\ flaviananunes@ufgd.edu.br \\ UFGD - Universidade Federal Grande Dourados
}

\begin{abstract}
RESUMO Neste texto pretendemos refletir sobre a pós-graduação brasileira no que concerne a dois grandes desafios: a integração entre ensino, pesquisa e extensão e a necessidade de outras formas de produção do conhecimento. Inicialmente, apontamos que a hegemonia da pesquisa assentada numa dada concepção de ciência e produção do conhecimento é um problema que limita e, muitas vezes, inviabiliza as relações ou articulações da pós-graduação com o ensino e a extensão. A partir disso, argumentamos sobre a necessidade de pensar o conhecimento produzido na pós-graduação para além da esfera reduzida da racionalidade cognitivoinstrumental da ciência moderna buscando outras formas de produção do conhecimento fora do âmbito acadêmico que dialoguem e estabeleçam trocas com o científico.
\end{abstract}

Palavras-chave: Ensino. Extensão. Pesquisa. Pós-Graduação. Produção do conhecimento.

ABSTRACT In this paper we intend to reflect on the Brazilian graduate regarding to two major challenges: the integration of teaching, research and extension and the need for other forms of knowledge production. Initially, we point out that the hegemony of the settler in a given conception of science and knowledge production is a problem limiting and often invalidate the relations or articulations of graduate with teaching and extension. From this, we argue about the need to think of the knowledge produced in the graduate program in addition to the reduced sphere of cognitive-instrumental rationality of modern science seeking other forms of knowledge production that communicate or establish exchanges with the scientific.

Keywords: Education. Extension. Research. Graduate School. knowledge Production.

\section{INTRODUÇÃO}

Este artigo resulta de um conjunto de reflexões inicialmente elaboradas para nossa participação na mesa redonda intitulada: "Desafios da Pós-Graduação no Ensino, Pesquisa e Extensão no contexto dos Institutos Federais” realizada no 
âmbito do III Seminário Integrado de Ensino, Pesquisa e Extensão do Instituto Federal Catarinense (IFC) ocorrido entre os dias 22 e 24/06/16 em Rio do Sul (SC). O evento teve como principal objetivo o aprofundamento da discussão e da compreensão do papel da pós-graduação no processo de integração entre ensino, pesquisa e extensão no contexto institucional, nacional e internacional ${ }^{1}$. Em vista dos objetivos do evento e da temática da mesa para a qual fomos convidados a participar, organizamos a reflexão em três momentos.

No primeiro momento, procuramos demonstrar as relações entre a hegemonia da pesquisa assentada numa dada concepção de ciência e produção do conhecimento que conferem ao ensino e à extensão uma colocação em patamares "inferiores" na hierarquia das atividades acadêmicas como um problema que limita e, muitas vezes, inviabiliza as relações ou articulações da pós-graduação com o ensino e a extensão.

No segundo momento, procuramos discutir sobre a necessidade de pensar o conhecimento para além da esfera reduzida da racionalidade cognitivo-instrumental da ciência moderna, buscando outras formas de produção do conhecimento que dialoguem e estabeleçam trocas com o científico.

No terceiro momento, a título de considerações finais, diante do quadro traçado nos dois primeiros momentos, apontamos algumas questões/possibilidades quanto aos desafios colocados para a pós-graduação no que se refere às articulações entre o ensino, pesquisa e extensão e outras formas de produção do conhecimento.

\section{A ARTICULAÇÃo ENTRE ENSINO, PESQUISA E EXTENSÃo A PARTIR DA PÓS-GRADUAÇÃO}

É possível a articulação entre ensino, pesquisa e extensão a partir da pósgraduação? Esse, certamente, é um grande desafio colocado para a pós-graduação brasileira, tendo em vista que sua estruturação e objetivos pautam-se majoritariamente na pesquisa, ou seja, pode-se dizer que "[...] os cursos de mestrado

\footnotetext{
${ }^{1}$ A temática central do evento foi firmada em torno do papel da pós-graduação para a consolidação da integração entre ensino, pesquisa e extensão, perpassando também outros temas, como internacionalização e práticas pedagógicas inovadoras.
} 
e doutorado constituem um lugar privilegiado de produção do conhecimento, dada a centralidade que a pesquisa científica deve neles assumir [...]" (SANTOS \& AZEVEDO, 2009, p. 42)

Embora Machado e Alves (2011, p. 08) salientem que os primórdios da pesquisa e da pós-graduação no Brasil não coincidem historicamente, destacam que o foco da pós-graduação é a pesquisa: "[...] Se é fato que o foco da pós-graduação é a pesquisa, é preciso ter clareza de que não são sinônimos e que a pesquisa antecede e excede a sua organização institucional, bem como a seus controles."

As autoras observam que "Pesquisa e pós-graduação conformam um sintagma que soa familiar no meio acadêmico. A denominação oficial das pró-reitorias, por exemplo, (com)porta essa expressão. [...]" (MACHADO; ALVES, 2011, p. 04)

A vinculação direta entre pesquisa e pós-graduação, no caso brasileiro, também pode ser identificada pelo fato de que:

[...] Embora muitos cientistas reivindicassem, desde os anos 1930, a ocupação do espaço universitário, a pesquisa só começará a se instalar como prática no meio acadêmico a partir da oficialização da pós-graduação (1965) [...] (MACHADO; ALVES, 2011, p. 09)

Ao discutir a trajetória da pós-graduação no Brasil, Gatti (2001) observa que nos anos 1970 e início dos anos 1980 os cursos e pós-graduação (mestrados e doutorados) foram criados, apoiados e sustentados num modelo voltado ao desenvolvimentismo e à formação de quadros para a pesquisa e para as universidades, dentro de uma certa concepção sobre ciência, sobre seu papel e os das tecnologias e sua produção/reprodução. Segundo a autora:

\footnotetext{
Mestrados e doutorados em nosso país originaram-se então, não do desenvolvimento da pesquisa científica nas universidades ou outras instituições, mas de uma política deliberada de organismos estatais, no final da década de 1960 e inícios de 1970. No ensino superior, à época, pouca pesquisa se desenvolvia, vez que sua vocação era dirigida sobretudo à formação de profissionais liberais. As universidades nasceram da agregação de cursos e pouquíssimas tinham a pesquisa como parte integrante do trabalho de seus docentes. (GATTI, 2001, p. 109)
}

Sendo assim, a autora aponta que a pesquisa foi induzida através da política de criação e apoio aos cursos de mestrado e doutorado, que passam a ser estimulados e financiados em sua implementação em algumas universidades que apresentavam maior solidez institucional. 
A pós-graduação, portanto, induziu a integração da pesquisa como parte da vida universitária, no entanto, no entendimento da autora, isso:

[...] acaba por criar uma vinculação excessiva entre a pesquisa e a pósgraduação na maioria das instituições, quando o desejável seria um espalhamento das atividades de investigação científica dentro de toda a vida acadêmica. $\mathrm{O}$ que se assistiu na maioria das instituições foi à concentração das atividades de pesquisa na pós-graduação, sendo aí o único espaço em que alguma pesquisa veio a ser realizada. (GATTI, 2001, p. 109).

Acredita-se que, se por um lado, a centralidade assumida pela pesquisa nos programas de pós-graduação tem permitido a elevação quantitativa e qualitativa das pesquisas realizadas em território nacional, por outro lado, essa centralidade tem relegado ao ensino e, principalmente à extensão, posições hierarquicamente inferiores à pesquisa não só no âmbito da pós-graduação, como da universidade de forma geral.

Em nosso entendimento, a hegemonia da pesquisa assentada numa dada concepção de ciência e produção do conhecimento que conferem ao ensino e à extensão uma colocação em patamares "inferiores" na hierarquia das atividades acadêmicas é um problema que limita e, muitas vezes, inviabiliza as relações ou articulações da pós-graduação com o ensino e a extensão. Moita e Andrade (2009, p. 277-278) salientam essa hierarquia:

\footnotetext{
Essa prática, que continua a reproduzir-se, está estruturada sobre uma clara hierarquia: se a graduação tornou-se o lugar do ensino, a pós-graduação tornou-se $o$ da pesquisa, sendo que tanto a extensão quanto o ensino são considerados tarefas inferiores à pesquisa. Na pós-graduação, a extensão é relegada, como se não pertencesse àquela indissociável articulação sobre a qual se fundamenta a universidade brasileira.[...]
}

A ideia de que a pesquisa seria uma atividade mais "nobre" ou mais "importante" do que o ensino e a extensão possui relação direta com a concepção de ciência e produção do conhecimento forjado entre os séculos XVII e XIX ainda bastante presente e arraigada nas estruturas institucionais e mesmo nas formas de pensamento daqueles que desenvolvem pesquisa.

A ciência moderna, pautada num modelo de racionalidade que se tornou, ao longo da história, um modelo global de racionalidade científica, trouxe consigo uma concepção de pesquisa que despreza e inferioriza outros saberes e formas de 
produção do conhecimento. Essa concepção de pesquisa estrutura, até os dias de hoje, a pós-graduação e a universidade de uma forma geral.

Um conjunto de pensadores, dentre os quais destacamos Boaventura de Sousa Santos (2007), têm analisado e problematizado a ciência moderna identificando, a partir de suas principais características, os limites desta forma de produção do conhecimento.

Para o autor, "[...] a racionalidade que domina no Norte tem tido uma influência enorme em todas as nossas maneiras de pensar, em nossas ciências, em nossas concepções da vida e do mundo." (SOUSA SANTOS, 2007, p. 25)

Seguindo Gottfried Leibniz, Sousa Santos (2007, p. 25) chama essa racionalidade hegemônica de indolente, preguiçosa:

[...] É uma racionalidade que não se exerce muito, que não tem necessidade de se exercitar bastante; [...] Então, o que estou tentando fazer aqui hoje é uma crítica à razão indolente, preguiçosa, que se considera única, exclusiva, e que não se exercita o suficiente para poder ver a riqueza inesgotável do mundo. Penso que o mundo tem uma diversidade epistemológica inesgotável, e nossas categorias são muito reducionistas.

Essa racionalidade, segundo o autor, produz ausências que se caracterizam pelo que chama de monoculturas: a monocultura do saber e do rigor; a monocultura do tempo linear; a monocultura da naturalização das diferenças que ocultam as hierarquias; a monocultura da escala dominante e a monocultura do produtivismo capitalista.

A monocultura do saber e do rigor refere-se à ideia de que o único saber rigoroso é o saber científico. Desta forma, outros conhecimentos não têm a validade nem o rigor do conhecimento científico. "Essa monocultura do rigor baseia-se, desde a expansão européia, em uma realidade: a da ciência ocidental." (SOUSA SANTOS, 2007, p. 29)

A monocultura do tempo linear baseia-se na concepção de que a história tem um único sentido, uma direção que apontam para a ideia de progresso caracterizado pelos países considerados desenvolvidos, que, portanto, estariam na dianteira. Logo, todos os países que são assimétricos com a realidade dos países mais desenvolvidos são considerados atrasados ou residuais. Sobre a organização do mundo e, 
consequentemente dos saberes numa trajetória em sentido único² Lander (2005) destaca que:

\begin{abstract}
A conquista ibérica do continente americano é o momento inaugural dos dois processos que articuladamente conformam a história posterior: a modernidade e a organização colonial do mundo. Com o início do colonialismo na América inicia-se não apenas a organização colonial do mundo, mas - simultaneamente - a constituição colonial dos saberes, das linguagens, da memória (Mignolo, 1995) e do imaginário (Quijano, 1992). Dáse início ao longo processo que culminará nos séculos XVIII e XIX e no qual, pela primeira vez, se organiza a totalidade do espaço e do tempo - todas as culturas, povos e territórios do planeta, presentes e passados - numa grande narrativa universal. Nessa narrativa, a Europa é - ou sempre foi simultaneamente o centro geográfico e a culminação do movimento temporal [...]. (LANDER, 2005, p. 10).
\end{abstract}

A naturalização das diferenças entre as quais se destacam a da classificação racial, étnica, sexual também constituem monocultura e ocultam as hierarquias. Segundo Sousa Santos (2007, p. 30): “[...] Esta é outra característica da racionalidade preguiçosa ocidental: não sabe pensar diferenças com igualdade; as diferenças são sempre desiguais.[...]"

A monocultura da escala dominante, por sua vez, caracteriza-se pela compreensão de que há uma escala dominante nas coisas. De acordo com Sousa Santos (2007, p. 31) essa escala dominante, na tradição ocidental, foi chamada de universalismo e mais recentemente de globalização. Tal compreensão destaca que o global é universal e hegemônico, desqualificando o particular e o local.

A quinta monocultura, a do produtivismo capitalista, baseia-se na ideia de que o crescimento econômico e a produtividade medida em tempo determinam a produtividade do trabalho humano ou da natureza e tudo aquilo que, neste contexto, não for produtivo, não contam, não são significativos.

Trazemos aqui as ideias de Sousa Santos, pois entendemos que são extremamente relevantes para pensarmos os fundamentos da racionalidade que embasa a concepção de pesquisa hegemonicamente presente e desenvolvida nas

\footnotetext{
${ }^{2}$ A geógrafa inglesa Doreen Massey também traz importantes reflexões sobre essa questão sob o ponto de vista espacial. Para ela, na modernidade: "(...) a diferença espacial era concebida em termos de sequência temporal. "Lugares" diferentes eram interpretados como estágios diferentes em um único desenvolvimento temporal. Todas as estórias de progresso unilinear, modernização, desenvolvimento, a sequência dos modos de produção [...] representava essa operação.[...]. (MASSEY, 2008, p. 107)
} 
universidades, sobretudo nos programas de pós-graduação brasileiros, independente da área de conhecimento.

Considerando-se principalmente a monocultura do saber e do rigor baseadas na ciência ocidental, a pesquisa científica adquire um status de superioridade em relação a outras formas de produção do conhecimento. Aqui referimo-nos a todos os tipos de conhecimentos produzidos fora da academia, como também aqueles gerados em atividades de ensino e extensão. Lamentavelmente, ainda se tem a concepção de que somente a pesquisa científica produz conhecimento e que o ensino apenas "reproduz" o conhecimento gerado pela pesquisa.

Quanto à extensão, a concepção mais comum é a de que esta se compõe de um conjunto de ações junto à comunidade, disponibilizando ao público externo o conhecimento advindo do ensino e da pesquisa desenvolvidos. Mesmo que sob o ponto de vista da justificativa de sua importância destaque-se que a extensão deve funcionar como uma troca de conhecimentos em que a universidade também aprende com a comunidade, uma ação que produz um novo conhecimento a ser trabalhado e articulado, verifica-se que, na maior parte das vezes, isto não se efetiva.

Ao defenderem a indissociablidade entre ensino, pesquisa e extensão na pósgraduação, Moita e Andrade (2009, p. 279) afirmam que:

[...] A extensão e o ensino não são acessórios à pesquisa, mas continuações naturais dela, se a produção científica do conhecimento quiser ser efetiva e intervir para modificar a realidade estudada - voltando a enriquecer-se, nesse processo, por dela alimentar-se continuamente.

Diante das questões até aqui destacadas sobre a concepção de ciência e produção do conhecimento que embasam a ideia de pesquisa na pós-graduação, passaremos, no tópico seguinte, a discutir outro desafio, diretamente ligado ou desdobrado desta problemática, que diz respeito à necessidade de rompimento e transgressão deste modelo de ciência pautado na lógica da racionalidade cognitivoinstrumental ocidental. 


\title{
3 AMPLIAR AS FORMAS DE PRODUÇÃO DO CONHECIMENTO
}

\author{
Além de identificar e problematizar os limites da produção do conhecimento no \\ âmbito da ciência moderna, Boaventura de Sousa Santos (2007) também propõe \\ algumas possibilidades que consideramos fundamentais para avançarmos neste \\ debate, sobretudo no que se refere a seus rebatimentos em relação à pesquisa na \\ pós-graduação e na universidade de forma geral. \\ É importante ressaltar que o autor não propõe o fim da ciência. Para Sousa \\ Santos (2007), necessitamos de um novo modo de produção do conhecimento, de \\ uma outra racionalidade. Em seu entendimento, não há ciência pura, há contato \\ cultural de produção da ciência e esta não é independente da cultura. Em suas \\ palavras:
}

\begin{abstract}
Não se trata de "descredibilizar" as ciências nem do fundamentalismo essencialista "anticiência"; como cientistas sociais, não podemos fazer isso. O que vamos tentar fazer é o uso contra-hegemônico da ciência hegemônica. Ou seja, a possibilidade de que a ciência entre não como monocultura mas parte de uma ecologia mais ampla de saberes, em que o saber científico possa dialogar com o saber laico, com o saber popular, com o saber dos indígenas, com o saber das populações urbanas marginais, com o saber camponês. Isso não significa que tudo vale o mesmo.[...] Somos contra as hierarquias abstratas de conhecimento, das monoculturas que dizem por princípio, "a ciência é única, não há outros saberes."[...] (SOUSA SANTOS, 2007, p. 32-33).
\end{abstract}

A ideia de que o saber científico deve dialogar com outros saberes é destacada a partir da constatação de que a experiência social em todo o mundo é muito mais ampla e variada do que a tradição científica ou filosófica ocidental considera importante. No entendimento do autor, essa riqueza social está sendo desperdiçada, portanto, é necessário combater o desperdício da experiência social a partir de um modelo diferente de racionalidade. (SOUSA SANTOS, 2004).

Essa racionalidade ele denomina cosmopolita:

A racionalidade cosmopolita proposta por Boaventura pretende reverter essa lógica, entendendo que se faz necessário expandir o presente sentido de criar as condições para o conhecimento e a valorização da inesgotável experiência social que está em curso no mundo de hoje (p. 779). [...] Uma vez conhecida a vastidão de experiências em curso na contemporaneidade, a possibilidade de compreendê-las em sua diversidade requer não mais uma teoria geral, mas a possibilidade de tradução, que crie uma inteligibilidade mútua entre as experiências de modo a não Ihes destruir a identidade. [...] (OLIVEIRA, 2008, p. 66). 
Ao sublinhar o conhecimento e a valorização da inesgotável experiência social que está em curso no mundo de hoje para construção de uma outra racionalidade, Sousa Santos aponta para o fato de que: "Toda experiência social produz e reproduz conhecimento e, ao fazê-lo, pressupõe uma ou várias epistemologias.[...]" (SOUSA SANTOS; MENEZES, 2009, p. 09)

Assim, o autor amplia o conceito de epistemologia entendendo que é:

[...] toda noção ou ideia, reflectida ou não, sobre as condições do que conta como conhecimento válido. É por via do conhecimento válido que numa dada experiência social se torna intencional e inteligível. Não há, pois, conhecimento sem prática e actores sociais, diferentes tipos de relações sociais podem dar origem a diferentes epistemologias. E como umas e outros não existem senão no interior de relações sociais, diferentes tipos de relações sociais podem dar origem a diferentes epistemologias.[...] (SOUSA SANTOS; MENEZES, 2009, p. 09).

A nosso ver, as proposições de Sousa Santos, principalmente aquelas que destacam a necessidade de combater o desperdício da experiência social a partir de um outro modelo de racionalidade, permitem refletirmos sobre o significado e papel da experiência na produção do conhecimento. Neste sentido, lembramos as ideias de Jorge Larrosa Bondía, professor de Filosofia da Educação na Universidade de Barcelona que possui um conjunto bastante interessante de reflexões sobre a experiência e sobre o que denomina saber de experiência. Para o autor, "a experiência é o que nos passa, o que nos acontece, o que nos toca. Não o que se passa, não o que acontece, ou o que toca. A cada dia se passam muitas coisas, porém, ao mesmo tempo, quase nada nos acontece. [...] (BONDÍA, 2002, p. 21)

No texto "Notas sobre a experiência e o saber de experiência", o autor procura demonstrar os motivos pelos quais a experiência no mundo de hoje é cada vez mais rara e apresenta seu entendimento sobre a experiência, o sujeito da experiência e o saber de experiência. Para o autor, o saber de experiência trata-se "de um saber distinto do saber científico e do saber da informação, e de uma práxis distinta daquela da técnica e do trabalho. O saber de experiência se dá na relação entre o conhecimento e a vida humana.[...]" (BONDÍA, 2002, p. 19)

O autor aponta como a ciência moderna distanciou-se do saber de experiência transformando a experiência em experimento: 
um elemento do método, isto é, do caminho seguro da ciência. A experiência já não é o meio desse saber que forma e transforma a vida dos homens em sua singularidade, mas o método da ciência objetiva, da ciência que se dá como tarefa a apropriação e o domínio do mundo. Aparece assim a ideia de uma ciência experimental. Mas aí a experiência converteu-se em experimento, isto é, em uma etapa no caminho seguro e previsível da ciência. A experiência já não é o que nos acontece e o modo como lhe atribuímos ou não um sentido, mas o modo como o mundo nos mostra sua cara legível, a série de regularidades a partir das quais podemos conhecer a verdade do que são as coisas e dominá-las.[...] (BONDÍA, 2002, p. 28).

Em seguida, apresenta as consequências desse distanciamento:

[...] Uma vez vencido e abandonado o saber da experiência e uma vez separado o conhecimento da existência humana, temos uma situação paradoxal. Uma enorme inflação de conhecimentos objetivos, uma enorme abundância de artefatos técnicos e uma enorme pobreza dessas formas de conhecimento que atuavam na vida humana, nela inserindo-se e transformando-a. A vida humana se fez pobre e necessitada, e o conhecimento moderno já não é o saber ativo que alimentava, iluminava e guiava a existência dos homens, mas algo que flutua no ar, estéril e desligado dessa vida em que já não pode encarnar-se. (BONDÍA, 2002, p. 28).

Guardadas as diferenças sob o ponto de vista da abordagem, objetivos e referências teórico-filosóficas, Sousa Santos e Bondía chamam atenção para a importância da experiência. No caso do primeiro, destaca-se a valorização da vastidão de experiências em curso no mundo atual para a construção de uma outra forma de racionalidade. No caso do segundo, chama a atenção para a importância do saber de experiência abandonado em nome do modelo a partir do qual se desenvolveu a ciência moderna.

Acreditamos que as reflexões desses autores nos permitem e impulsionam a pensar e questionar: em que medida a desvalorização de inúmeras experiências e o distanciamento do saber de experiência contribuíram para uma forma de produção do conhecimento hegemonicamente praticada (a pesquisa científica) que desvaloriza e desconsidera saberes e conhecimentos gerados no ensino e na extensão?

Quantas experiências e saberes produzidos em atividades de ensino e extensão foram e são cotidianamente "desperdiçados" em nossas universidades e que poderiam constituir-se não só em material ou objeto de pesquisa (como em muitos casos já são), como também poderiam articular e ampliar a compreensão e as formas de produção do conhecimento na pós-graduação? 
Entendemos, portanto, que outro grande desafio posto à pós-graduação e que se articula diretamente ao tratado no tópico anterior deste texto, está na necessidade de pensar o conhecimento produzido na pós-graduação para além da esfera reduzida da racionalidade cognitivo-instrumental da ciência moderna buscando outras formas de produção do conhecimento que dialoguem estabeleçam trocas com o científico.

\section{CONSIDERAÇÕES FINAIS}

Em vista dos dois grandes desafios postos à pós-graduação neste texto: a articulação entre ensino, pesquisa e extensão e o diálogo com outras formas de produção do conhecimento, não é possível trazermos aqui soluções definitivas e absolutas; apontaremos apenas algumas possibilidades.

Inicialmente, acreditamos na necessidade de construção, nos programas de pós-graduação, de uma perspectiva em que a pesquisa em si não seja a prioridade. É fundamental que a pesquisa não apenas derive das atividades de ensino e/ou extensão, mas que as integre, que estabeleça o diálogo com elas, que se nutra delas, ao mesmo tempo em que possa estruturá-las numa via de mão dupla.

Entendemos que a ampliação das formas de conhecimento na pós-graduação está diretamente relacionada ao diálogo e trocas que podem e devem ser estabelecidas com as experiências e saberes produzidos nas atividades de ensino e de extensão.

No entanto, para que tais possibilidades se configurem concretamente, há reflexões que as antecedem. Será necessário que o conjunto de sujeitos e instituições envolvidas com os programas de pós-graduação discuta sobre quais pesquisas 0 programa desenvolverá. Como serão construídas as problemáticas e questões das pesquisas a serem desenvolvidas no âmbito do programa de pós-graduação é uma resposta que pode dar a dimensão das relações desta com o ensino e com a extensão.

Para além disso, deve-se questionar: qual(is) concepção(ões) de ciência e produção do conhecimento estarão na base das pesquisas a serem realizadas na pósgraduação? As respostas e reflexões em torno desta questão, poderão sinalizar os caminhos no sentido da superação dos desafios postos à pós-graduação abordados neste texto. 


\section{FLAVIANA GASPAROTTI NUNES}

Possui Licenciatura em Geografia pela Universidade Estadual Paulista Júlio de Mesquita Filho (1997), mestrado (2000) e Doutorado (2004) em Geografia pela Universidade Estadual Paulista Júlio de Mesquita Filho. Realizou Estágio de PósDoutorado na Universidade Federal do Rio de Janeiro (2011). Atualmente é professora associada da Universidade Federal da Grande Dourados.

\section{REFERÊNCIAS}

BONDÍA, J. L. Notas sobre a experiência e o saber de experiência. Revista Brasileira de Educação, Rio de Janeiro, s/v., n 19, p. 20-28, Jan/Fev/Mar/Abr, 2002.

GATTI, B. A. Reflexão sobre os desafios da pós-graduação: novas perspectivas sociais, conhecimento e poder. Revista Brasileira de Educação, Rio de Janeiro,s/v, no 18, p.108-116, Set/Out/Nov/Dez, 2001.

LANDER, E. Ciências sociais: saberes coloniais e eurocêntricos. In: LANDER, E. (Org.). A colonialidade do saber: eurocentrismo e ciências sociais. Perspectivas latino-americanas., Buenos Aires: CLACSO, Ciudad Autônoma de Buenos Aires, Argentina, 2005, p. 08-23. (Colecion Sur-Sur).

MACHADO, A. M. N.; ALVES, V. Caminhos ou (des)caminhos da Pós-Graduação Stricto Sensu em educação no Brasil. In: 28 ${ }^{\underline{a}}$ REUNIÃO ANUAL da ASSOCIAÇÃO NACIONAL DE PÓS-GRADUAÇÃO E PESQUISA EM EDUCAÇÃO, 2005, Caxambu, MG, Brasil. Anais..., 2005, p. 01-16.

MASSEY, Doreen. Pelo espaço: uma nova política da espacialidade. Rio de Janeiro: Bertrand Brasil, 2008.

MOITA, F.M.G.da S.C.; ANDRADE, F.C.B. Ensino-pesquisa-extensão: um exercício de indissociabilidade na pós-graduação. Revista Brasileira de Educação, Rio de Janeiro, v. 14, n. 41, p. 269-280, Maio/Ago, 2009.

OLIVEIRA, I. B. de. Boaventura \& a Educação. Belo Horizonte: Autêntica, 2008.

SANTOS, A. L. F. dos; AZEVEDO, J. M. L. A pós-graduação no Brasil, a pesquisa em educação e os estudos sobre a política educacional: os contornos da constituição de um campo acadêmico. Revista Brasileira de Educação, Rio de Janeiro, v. 14 n. 42, p. 534-550, Set./Dez. 2009.

SOUSA SANTOS, B. de. Por uma sociologia das ausências e uma sociologia das emergências. In: (Org.) Conhecimento prudente para uma vida decente. São Paulo: Cortez, 2004, p. 777-823.

. Renovar a teoria crítica e reinventar a emancipação social. São Paulo: Boitempo, 2007. 
Para além do pensamento abissal: das linhas globais a uma ecologia de saberes. In: SANTOS, Boaventura de S.; MENEZES, Maria P. (Orgs).

Epistemologias do Sul. Coimbra: Almedina, 2009, p. 23-72. 